\title{
Constructing Approaches of Teachers' Practical Knowledge in Vocational Colleges
}

\author{
Wang Caixia Liu Guangran \\ Information and Technology College \\ Tianjin University of Technology and Education \\ Tianjin, China \\ wcx14@126.com
}

\begin{abstract}
Practical knowledge was very important for professional development of teachers in vocational colleges. In vocational colleges, constitutes of teachers' practical knowledge included not only self-knowledge, knowledge of the subjects, students' knowledge, and knowledge of the scenario , but also vocational skills and teaching experience in the professional training of teaching scene. In accordance with the special law of vocational education and the principle of knowledge conversion, teachers' practical knowledge in vocational colleges was constructed by watching demonstration lessons, practicing in enterprise, writing educational narrative based on reflection and action research.
\end{abstract}

Keywords-vocational colleges; teachers' practical knowledge;explicit kowledge;knowledge conversion

\section{INTRODUCTION}

Many scholars believed that teachers' practical knowledge was an important part of teachers' knowledge. According to professor Yelan's opinion, the wealth of practical knowledge was important in the growth and development of teachers, and the profession of teachers relied on practical knowledge, which teacher used the comprehensive insight to expand the awareness of the problem and problem solving maturity. [1]This paper mainly discussed the structure of teachers 'practical knowledge in vocational colleges, then put forward the ways of constructing teachers' practical knowledge.

\section{TEACHERS' KNOWLEDGE}

About definition of teachers' knowledge, many scholars had given different definition, according to Manabu Sato's opinion, who was Japanese scholar, teachers' personal knowledge was practical knowledge, which depended on certain background (concepts, beliefs, and values), and was summed up from experiential knowledge in practice. Compared with conceptual knowledge which was used by other researchers, practical knowledge was multi-righteous and the lack of rigor and universality, but it was functional knowledge which had a certain performance. According to zhang lichang's opinion, teachers' personal knowledge was effectiveness knowledge which was summed up by teachers in specific teaching practice situational through their own experience, meditation, feelings and understands. Practical knowledge was obtained and updated in the selfdeconstruction and constantly reconstructed by individual as subject, practice as a way and reflection as strategy.
According to the extensive literature, many scholars at home and abroad thought that teachers' practical knowledge was an important part of teachers' knowledge.

\section{THE STRUCTURE AND CHARACTERISTICS OF TEACHERS' PRACTICAL KNOWLEDGE}

Teachers' practical knowledge was formed and refined by teachers reflecting on their own teaching experience, and teachers' practical knowledge was applied and practiced through teaching action. [2]Teachers'practical knowledge mainly included self-knowledge, knowledge of the subjects, students' knowledge, and knowledge of the scenario. [2]The four aspects of teachers' practical knowledge were influenced by the teachers' educational beliefs. Characteristics of teachers' practical knowledge included practicality, situationality and tacit, individuality and interactivity.

\section{A. practicality}

Teachers' practical knowledge came from practicing, and pointing in practicing. The specific problems in the practice were a direct incentive for teachers to construct practical knowledge, and practice was the starting point and end point of the practical knowledge of teachers. Knowledge which teachers accumulated through the practice continued to be updated and deepened, in result it was turned into education philosophy of teacher.

\section{B. Situationality}

Practical knowledge was to explore the specific teaching problem in the particular context, such the specific time, place, and person. At the same time, practical knowledge provided cases and suggestion to the similar educational context.

\section{Tacit}

Teachers' practical knowledge was a special kind of tacit knowledge, which existed in the daily lives of teachers and teaching experience. Practical knowledge was formed for teachers in unaware of the way, which was difficult to use language and writing to express.

\section{Individuality}

Teacher was the main body of the practice, and their practical knowledge in specific teaching scenarios was affected by teachers' personal experiences, subjective beliefs, values and experience, so the cognitive results of teacher was 
not the same, and teacher formed practical knowledge of the personality.

\section{TEACHERS' PRACTICAL KNOWLEDGE IN VOCATIONAL COLLEGES}

The fundamental task of the vocational education was to train highly skilled talented person who serviced the needs of the society in production, construction, management, and met the needs of society as a fundamental objective, so it required students to have a strong practical ability. So, teachers of vocational colleges had not only theoretical knowledge, but also professional skill, who was called "Double-professionally-titled Teachers". They must have certain professional practice, and the specific performance were the practical ability and guiding practice teaching ability.So,in vocational colleges, constitutes of teachers' practical knowledge had self-knowledge, knowledge of the subjects, students' knowledge, and knowledge of the scenario , but also vocational skills and teaching experience in the professional training of teaching scène. Practical knowledge was the professional value for teachers in vocational colleges. The teachers should think that practical knowledge was the basis, and realize their own wisdom and strength, but also find a space of their own professional development, in order to promote the professional development of teachers.

\section{CONSTRUCTION OF TEACHERS' PRACTICAL KNOWLEDGE IN VOCATIONAL COLLEGES}

In vocational colleges, sources of teachers' practical knowledge mainly had three aspects:(1)conversion of the knowledge of educational theory and professional theory;(2)accumulation of teachers' long-term practice of classroom teaching experience, and(3) practice of teachers in specific training site or off-campus enterprise. Teachers' practical knowledge was automatically generated in a specific cultural context, which implicated in the words and deeds of the people and could be felt but unspeakable. The practical knowledge of teachers must be converted to let knowledge flow, share, communicate and store.Nonaka who was scholars in Japan proposed the model of knowledge conversion, On this basis, this paper presented the model of teachers' knowledge conversion shown in figure1.

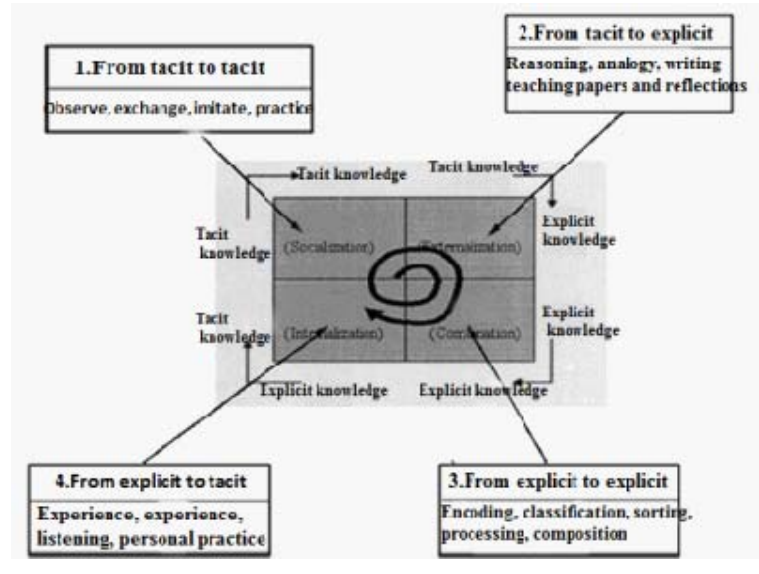

Figure 1 The model of teachers' knowledge conversion

From above figure, teacher' practical knowledge was transformed through socialization 、 internalization and externalization. Therefore, teachers' practical knowledge in vocational colleges was constructed by the following ways.

\section{A. Watching demonstration classes}

The demonstration classes as boutique which were formed by testing at every point and embodied teaching experience and wit of excellent teachers, were complexity of explicit knowledge and tacit knowledge of teachers. Watching demonstration lessons realized internalization of teachers' practical knowledge, knowledge sharing and exchange, and the flow of knowledge among teachers. Watching demonstration lessons, we could analyze the characteristics of teaching behavior, organizational forms of the classroom and teaching ideas, so as to absorb reasonable information and experience in teaching, and mine practical knowledge dependent on specific educational events. After this knowledge was integrated into the cognitive structure of teachers, they could be internalized into practical knowledge of individual teachers. Demonstration lessons were excellent off-the-shelf video teaching cases or teaching scene. Video teaching cases generally came from educational resource library in college or the Internet, which could be paused, reminded and repeatedly observed, in addition, it also came from observing the teaching scene, where you could feel the atmosphere in the classroom, learn teaching skills and expertise of the instructor. Training teaching was the most important form of teaching in vocational colleges. Through observing demonstration lessons, teachers could not only imitate the operation of professional skills, but also enhance the practical knowledge of guiding training teaching.

\section{B. Writing educational narrative based on reflection}

Teachers' practical knowledge was showed through specific teaching scene, with the characteristics of complicated, unstable, and fleeting. If the practical knowledge of teachers was not conscious to pay attention and intervene, a part of the experience would be lost because you forget to save, and a part of the experience in mind existed in the wrong form because of the lack of timely review and clarify. The other part of the experience which 
could not been coded and summarized, was not easy to be found at any time. Writing educational narrative on the base of reflection, practical knowledge could be externalization and preserved in long-term. When writing educational narrative, it was very important to fully embody the concept of reflection, which was not just a simple description for teaching classroom and stories in education, but "narrative and discussion", on the base of full original course of events presented, by inserting personal feelings, attitudes, motives and perspectives. In the teaching narrative "Committed, said, think, feel" should be embodied. The following has been noted.

(1) Present form: by narrative and discussion, the content was long or short, according to the specific circumstances of the incident, which could be performed by text, pictures and video etc.

(2) Content: the main object described was some of the real events occurring in teaching, and the content included the characters, plot, and problems of the event which reflected the theme of teaching and educational ideas.

(3)Tools: there were many online tools which were available for teachers to write the narrative of education, such as the popular blog which was personal information release system, and teachers could apply for their own blog, and then write educational narrative.

\section{Practicing in enterprises}

Due to the ongoing changes in the vocational areas, and close contact between vocational education and the economy of society, teachers' professional knowledge and skills must evolve with the development of technology and the changes of corporate organizational model. Teachers in vocational colleges should pay close attention to the technical knowledge of professional frontier and state-of-the-art production equipment, in order to apply them in teaching. [3] Teachers in vocational colleges through the company practice and training, could enrich work experience in corporate , enhance vocational skills and practical teaching ability, so, company practice had become an important way of training "Double-professionally-titled" Teachers. Vocational colleges had actively explored and established the system of enterprise practice for teachers, and try hard to explore some ways of enterprise practice which were diversity, innovation, effectiveness. There were generally three forms for teachers to practice in company :(1) teachers were organized by vocational college to visit company during the holidays, in order to understand the production process and workshop process. (2) In-service teachers practiced in enterprises about one or two months every two years, and the new teachers practiced in the enterprise for a period of time. And (3) teachers and students went together enterprises to practice, in this way; we could reduce the burden for businesses, but also teachers and students to learn together, both teaching and learning.

The teachers in vocational colleges should cherish the opportunity of professional practice in the enterprises, during the practice, Theoretical knowledge of teachers was transformed into professional skills, and teacher could understand the social needs of profession. Through practice in enterprises, the theoretical knowledge of teachers would be deepened and teachers' practical knowledge would be promotion.

\section{Participating in subject study, and carrying out action research}

When participating in research team, teachers in vocational college could internalize explicit knowledge into their own wisdom, to quickly construct their own knowledge. By the project, teachers would build up connection between educational theory and educational practice, and update their knowledge. In the process of this, explicit knowledge would be internalized. Meanwhile, knowledge of teachers would be applied and innovated by curriculum development and innovative teaching. Under normal circumstances, the research team was composed of a number of specialized researchers, such as professors of university, experts in other educational institutions and first-line teachers. In the research community, the experts and professors had extensive knowledge about educational theory, and teachers had the practice knowledge in teaching. In the process of collaborative research, knowledge among team members continued to convert and upward spiral. In the process of dynamic transformation of knowledge, it enabled teachers to constantly enrich and improve individual's knowledge, and in the exchange and sharing, knowledge would be updated and created to improve professional standards of teachers. In the research community, knowledge conversion was shown in figure2.

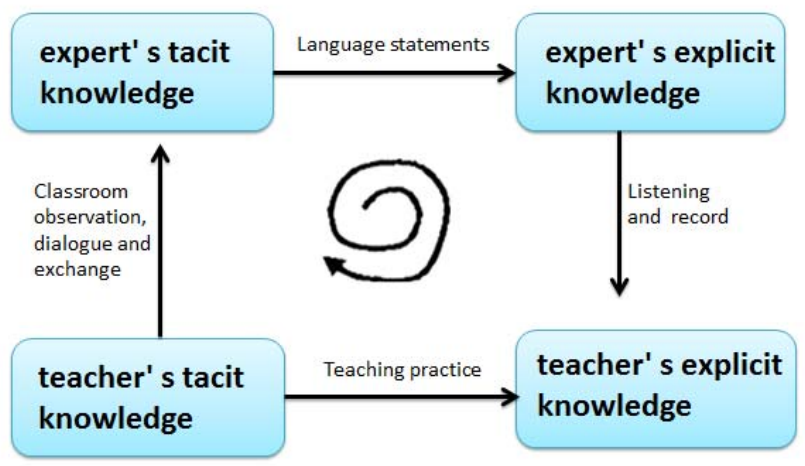

Figure 2 process of knowledge conversion

It could be seen from the figure, when the front-line teachers joined the research team of project and carried out action research, teacher could internalize explicit knowledge into their own practical tacit knowledge. As a result that knowledge would be applied and innovated to enhance comprehensive professional ability.

\section{CONCLUSION}

In accordance with the composition and characteristics of teachers' practical knowledge in vocational colleges, some ways were put forward about constructing practical 
knowledge. In addition, some systems should be built for the construction of teachers' practical knowledge.

Teachers should establish correct concept of education, focus on its own development, and use some network tools to facilitate the conversion and storage of practical knowledge.

\section{ACKNOWLEDGMENT}

provide funds, and also thank the other members of the research group. In the course of the study, some literature was referred, thank the authors.

\section{REFERENCES}

[1] Ye Lan, Exploration of the role of teacher and teacher development, Education and Science Press:Beijing,2001,pp. 215- 216

[2] Chen Xiangming, Build a bridge of practice and theory - research of teachers' practical knowledge , Education and Science Press:Beijing,2001,pp.77-78.

[3] Liuming, Vocational colleges - capacity building and management of teacher, China Science and Technology Press:Hefei,2012,pp16-17.

[4] Connelly, F. M, Clandinin, D. J. Teachers Personal Practical knowledge on the Professional Knowledge Landscape,Teaching aml Teacher Education, July,1997.

[5] F. Michael Connelly, D. Jean Clandinin. Teachers' Persanal Practical Knowledge on the Profes-sional Knowledge Landscape ,Teaching and Teacher Education,July,1997.

[6] Nico Verloop, Jan Van Driel and PaulienMeijer,Teacher knowledge and the knowledge base of teaching, InternationalJournal of Educational Research,May , 2001.

[7] PolanyMiehael,PersonalKnowledge,Chieago:The University of Chieago Press, 1958.

[8] Sehon.DA.theRefraetionalPraetioner:HowProfessionalsthinkinAetion. .NewYOrk.Basiebook,1983.

[9] ElbazE, The teaeher's Praetieal knowledge,RePort of case study.CurrieulumInquiry, November, 1981.
This study was funded by " Research and Practice of Promoting Approach about Teaching Practice Ability for Teachers in Vocational College " which was Educational Science Planned Research Topics in Tianjin (project number: VE3005). Thank you very much for this study to 